\title{
Sustained release of carmustine (BCNU) for treatment of experimental intraocular malignancy
}

\author{
LUKE H. S. LIU, ' MIGUEL F. REFOJO, ${ }^{1}$ CHUO NI,' NORIO UENO,' \\ AND DANIEL M. ALBERT \\ From the ${ }^{1}$ Eye Research Institute of Retina Foundation and ${ }^{2}$ Harvard Medical School, Boston, \\ Massachusetts 02114, USA
}

SUMMARY Sustained release of carmustine (1,3-bis[2-chloroethyl]-1-nitrosourea, or BCNU) via an episcleral implanted silicone device was used to treat Greene hamster melanoma implanted in the anterior chamber of rabbit eyes. Group 1 animals received carmustine intravenously; group 2 received the drug by local sustained release via an episcleral implanted silicone device; group 3 received the drug by both local sustained release and intravenous injection (a total dosage more than twice that in group 1); and group 4 was not treated. The effectiveness of the various administration routes was compared by clinical observation of tumour size and systemic and local toxic reactions, and by histopathological examination. Carmustine delayed the growth of Greene melanoma in all 3 treated groups, but was most effective when a lower dose of the drug administered intravenously was combined with an additional higher dose administered by local sustained release. Local side effects included corneal clouding and conjunctival oedema and congestion at the early stage of local drug delivery via the episcleral implanted device.

Both sustained release of carmustine (1,3-bis[2chloroethyl]-1-nitrosourea, or $\mathrm{BCNU}$ ) from an implanted silicone device in mice carrying L1210 leukaemic cells and direct intraneoplastic injection of the drug in a mouse brain tumour model have produced good results. ${ }^{1-3}$ In recent years we have applied these methods of treatment to intraocular malignancies in animals, with encouraging results. ${ }^{45}$

We have established the maximum tolerable doses of carmustine in normal rabbits for intraocular, periocular, and topical routes of drug administration. ${ }^{67} \mathrm{We}$ have also studied the release rate of carmustine from a silicone device in vitro and the pharmacokinetics of this drug in the aqueous and vitreous of rabbits after intravenous and subconjunctival injections and topical application. ${ }^{89}$

We have developed a local sustained-release system that employs an episclerally implanted microsilicone device to deliver carmustine for treating BrownPearce epithelioma in rabbit eyes. ${ }^{4}$ Subsequently we have treated the Greene hamster melanoma, grown in the anterior chamber of rabbits, with periocular

Correspondence to Dr L. H. S. Liu, Eye Research Institute, 20 Staniford Street, Boston, MA 02114, USA. injections of carmustine. ${ }^{5}$ In the current study we have used the sustained-release system to treat Greene melanoma in the anterior chamber of the rabbit.

\section{Materials and methods}

The silicone device is made of 2 sheets of silicone rubber. The peripheral edges of the sheets are glued together with silicone adhesive, except where a small unidirectional silicone tube, permitting one-way injection of drugs into the pocket of the device, is sandwiched between them. When drug is injected into the unidirectional silicone tube, the device expands (Fig. 1). The details of the device and the method of its implantation have been described previously. ${ }^{4}$ The release rate of carmustine from the device in vitro and in vivo has been reported. ${ }^{89}$ Carmustine in absolute ethanol in the device resulted in rapid diffusion of the alcohol, leaving essentially pure carmustine. Consequently the release rate of carmustine is essentially constant for a period of time that depends on the amount of drug present.

Young female albino New Zealand rabbits 

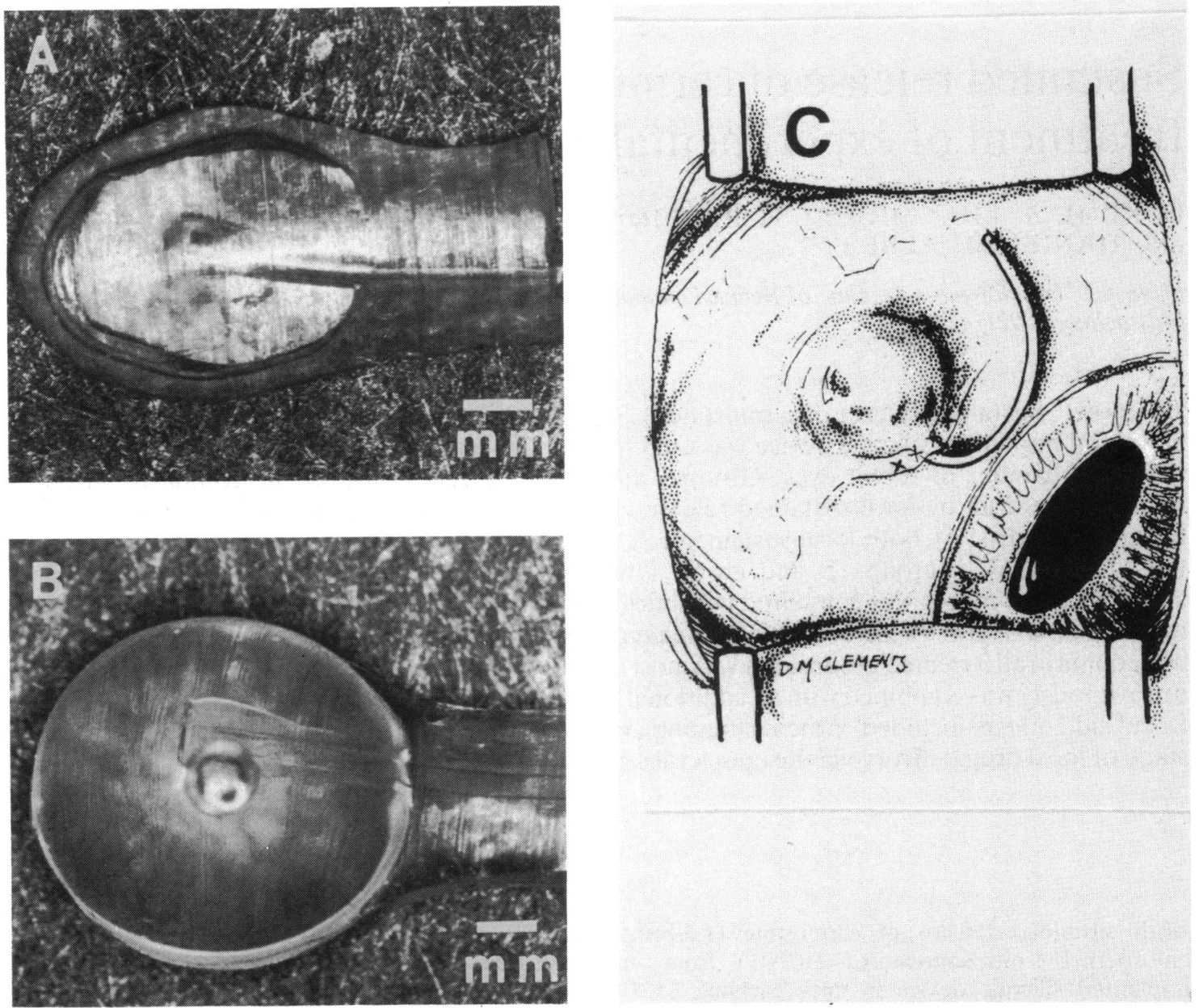

Fig. 1 Silicone device. (A) Before injection. (B) After injection of alcoholic solution of carmustine. (C) After episcleral implantation and injection of alcoholic solution of carmustine.

weighing about $1 \mathrm{~kg}$ each were examined by biomicroscopy, tonometry, and indirect ophthalmoscopy. All animals had normal eyes. Both eyes of each animal were inoculated intracamerally with a small piece of Greene melanoma tissue, approximately $0.5 \mathrm{~mm}^{3}$ in size $\left(6 \times 10^{6}\right.$ cells $)$ that had been passaged 30 times in rabbit eyes. Tumour growth could be clinically recognised in the anterior chamber about 10 days after tumour tissue was inoculated. Tumours developed in both eyes in 18 animals and in one eye in 17 rabbits for a total of 53 eyes with tumours.

Nine animals (18 eyes) (group 1) received carmustine intravenously. Three animals ( 6 eyes) (group 2) received the drug via an episcleral implanted silicone device. Seventeen animals (17 eyes) (group 3) received carmustine both from local sustained release via an implanted device and from intravenous injection; the total dose was more than twice the dose in group 1 . Six animals (12 eyes) served as untreated controls.

Treatment was started immediately after the implanted tumour was recognised as growing in the anterior chamber and could be plainly seen. Table 1 shows the protocol details. The implanted device was removed when treatment was completed. Ocular examinations were repeated on alternate days during the follow-up period of 30 to 60 days. The effectiveness of treatment was evaluated by (1) comparing the extent of tumour growth in the anterior chamber; (2) noting the occurrence of local complications after local sustained release of carmustine and noting the distortion and perforation of the eye caused by tumour extension; (3) observing the animals for 
Table 1 Administration of carmustine to tumour model

\begin{tabular}{|c|c|c|c|c|}
\hline Group, route & No. of eyes & Dose, $m g$ & Dose schedule & Total dose, $m g$ \\
\hline $\begin{array}{l}\text { Untreated control } \\
\text { 1. Intravenous } \\
\text { 2. Local sustained release } \\
\text { 3. Intravenous + local sustained } \\
\quad \text { release }\end{array}$ & $\begin{array}{l}12 \text { (in } 6 \text { rabbits) } \\
18 \text { (in } 9 \text { rabbits) } \\
6 \text { (in } 3 \text { rabbits) } \\
17 \text { (in } 17 \text { rabbits) }\end{array}$ & $\begin{array}{l}- \\
4 \cdot 0 / \mathrm{kg} \text { body weight } \\
2 \cdot 0 / \mathrm{eye} \\
4 \cdot 0 / \mathrm{kg} \text { body weight } \\
+2 \cdot 0 / \text { eye }\end{array}$ & $\begin{array}{l}\text { Once a week for } 3 \text { weeks } \\
\text { Once a day for } 8 \text { days } \\
\text { Once a week } \times 3 \\
+ \text { once a day } \times 8\end{array}$ & $\begin{array}{l}\text { - } 12 \cdot 0 / \mathrm{kg} \text { body weight } \\
16 \cdot 0 / \mathrm{eye} \\
12 \cdot 0 / \mathrm{kg} \text { body weight } \\
+16 \cdot 0 / \text { eye }\end{array}$ \\
\hline
\end{tabular}

Table 2 Clinical results 15 days after start of carmustine treatment

\begin{tabular}{llccc}
\hline Group, route & $\begin{array}{l}\text { No. of } \\
\text { eyes }\end{array}$ & $\begin{array}{l}\text { Tumour eradicated or } \\
\text { confined to iris }\end{array}$ & Tumour filled eye \\
\hline Untreated control & 12 & 0 & 0 & Eye perforated \\
$\begin{array}{l}\text { 1. Intravenous } \\
\begin{array}{l}\text { 2. Local sustained release } \\
\text { 3. Intravenous + local sustained }\end{array}\end{array}$ & 18 & 14 & 2 & 0 \\
$\quad$ release & 17 & 6 & 12 & 0 \\
\hline
\end{tabular}

Table 3 Clinical results 30 days after start of carmustine treatment

\begin{tabular}{lllcr}
\hline Group, route & $\begin{array}{l}\text { No. of } \\
\text { eyes }\end{array}$ & $\begin{array}{l}\text { Tumour eradicated or } \\
\text { confined to iris }\end{array}$ & Tumour filled eye \\
\hline $\begin{array}{l}\text { 1. Intravenous } \\
\text { 2. Local sustained release }\end{array}$ & 18 & 3 & 4 & 11 \\
$\begin{array}{l}\text { 3. Intravenous + local } \\
\quad \text { sustained release }\end{array}$ & 6 & 2 & 1 & 3 \\
\hline
\end{tabular}

systemic toxic reaction as indicated by general activity, appetite, body weight, and white blood cell count; and (4) comparing the histopathological changes of the tumours.

Test eyes were enucleated at 30 days or when they perforated if this occurred before 30 days. Enucleated eyes were prepared for histopathological examination by fixation in $10 \%$ buffered formalin solution (final concentration of formaldehyde $3 \cdot 7 \%$ ). A sagittal section was made on either side of the optic nerve, and the pupil-optic nerve sections and the 2 calottes were processed routinely for histological evaluation. Haematoxylin-eosin ( $\mathrm{H}$ and $\mathrm{E}$ ) stain was used. The eyes were embedded in paraffin and sectioned for light microscopy. Sections $6 \mu \mathrm{m}$ thick were cut, and every fifth section was stained. About 50 sections from each eye were examined.

\section{Results}

\section{CLINICAL OBSERVATIONS}

The clinical results 15 days after start of treatment are given in Table 2 and 30 days after start in Table 3.

Control eyes. In the 12 untreated eyes the implanted Greene melanoma usually entirely filled the anterior chamber within 10 to 12 days after the tumour started to grow. All 12 eyes were distorted and perforated as a result of tumour expansion within 15 days.

Group 1: Intravenous injection of carmustine. At day 15 after the start of treatment tumour growth was slower in 16 of the 18 test eyes than in the control eyes. By day 30, 11 eyes were perforated. The body weight of each animal increased steadily.

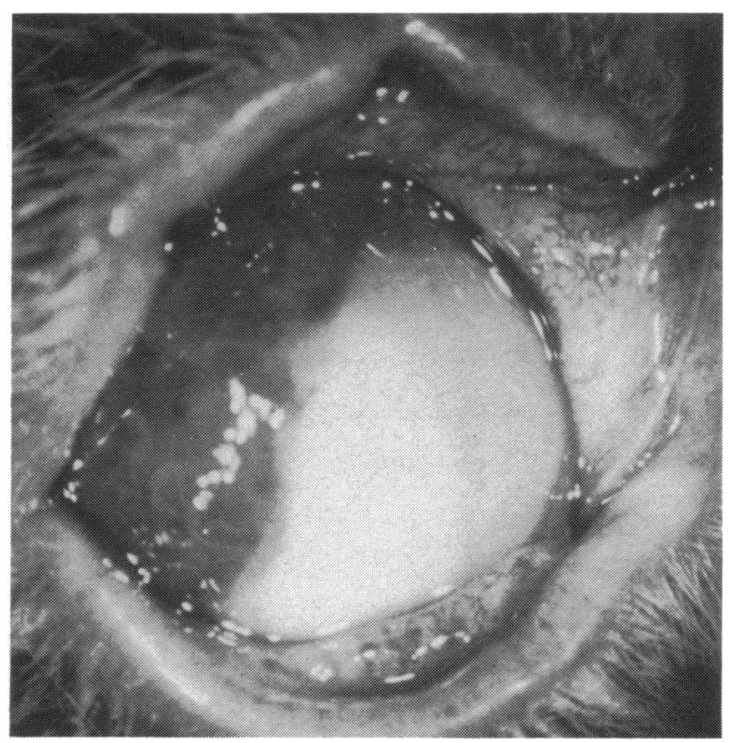

Fig. 2 Corneal opacity persisting 4 weeks after cessation of treatment with local sustained release of carmustine (group 2 eye). 


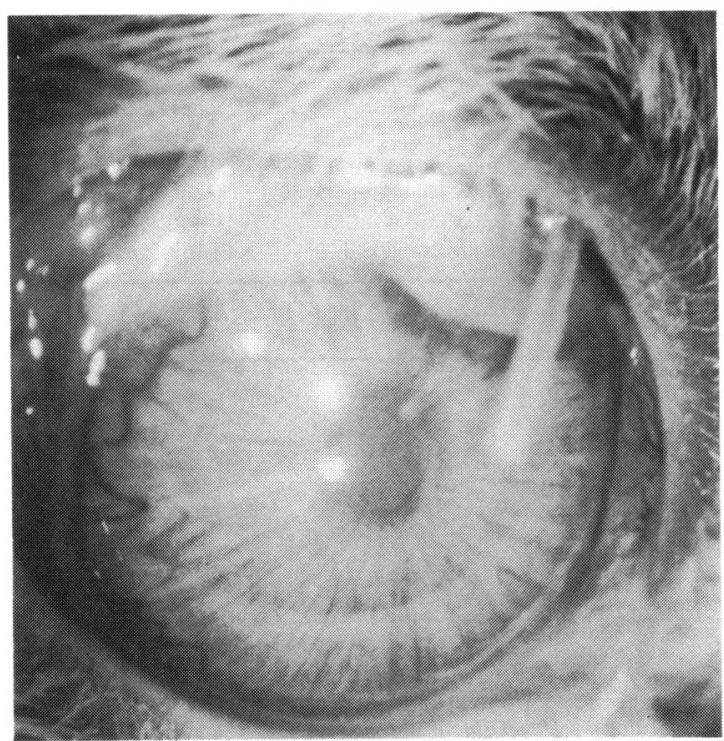

Fig. 3 Tumour confined to iris 15 days after combined local and systemic treatment (group 3 eye).

Group 2: Local sustained release of carmustine. At day 15 tumour growth was slower in all 6 test eyes than in the controls; none of the eyes was filled with tumour or perforated. By day 30, 3 eyes were perforated. The body weight of each animal increased steadily. Almost all eyes showed local side effects, including corneal clouding and conjunctival oedema and congestion at the early stage of local drug delivery

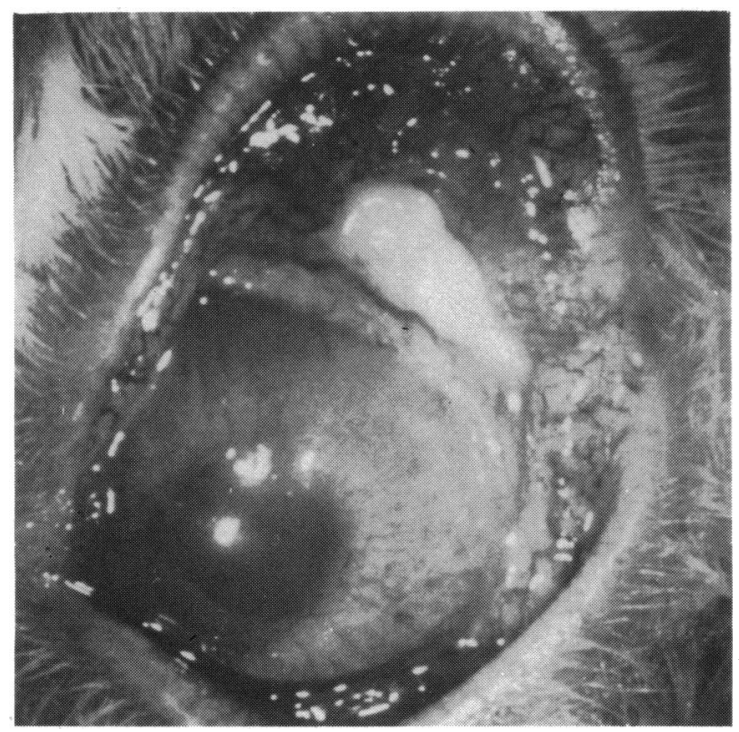

Fig. 4 Abscess formation at the site of implanted silicone device (group 3 eye). via the implanted device. These side effects subsided about one week after treatment ended except for one eye in which corneal opacity remained 4 weeks after treatment ended (Fig. 2).

Group 3: Combined local and systemic delivery of carmustine. At day 15 tumour growth was slower in all 17 test eyes (Fig. 3) than in the controls. By day 30,7 eyes were perforated. No systemic toxic reactions were noted except in 2 animals whose body weight increased slowly after treatment but began to increase steadily again 4 weeks after treatment ended. Local late complications included abscess formation surrounding the implanted device in 2 eyes (Fig. 4).

\section{HISTOPATHOLOGICAL OBSERVATIONS}

Control eyes. In the control group of 6 rabbits the 12 eyes were enlarged, and the spaces in the anterior segment and vitreous cavity were filled with the tumour. The iris and ciliary body were completely replaced by tumour tissue. The retina was detached and disorganised. The choroid and sclera were partially infiltrated by tumour cells. The globe was perforated over one side at the pars plana. The optic nerve was atrophic. Massive necrosis associated with extensive haemorrhages was present in a large part of the tumour. The tumour cells were of varied appearance; most were plump spindle cells with obvious nucleoli. Mitotic figures were frequently seen.

Group 1: Intravenous injection of carmustine. Of the 18 eyes in this group in 15 the tumour filled all the spaces of the eye except a small portion of the posterior vitreous cavity (about $10 \%$ of the eyeball). In 11 eyes a large number of tumour cells infiltrated the cornea and sclera, splitting the corneal and scleral lamina and perforating the eye at the limbus. The tumour formed a collar-like configuration round the blood vessels; necrosis was seen in tissue peripheral to the vessels. The retina and choroid were partly destroyed by tumour. In 3 eyes the tumours were confined to the iris.

Group 2: Local sustained release of carmustine. Of the 6 eyes in this group 3 maintained normal shape and size; in one of the 3 the tumour filled the anterior chamber. The ciliary body and the anterior part of the choroid were also involved in one of these eyes. The tumours of 3 perforated eyes were similar in appearance and extent of involvement to those of group 1 (control) animals. Necrosis of the conjunctiva and the peripheral part of the cornea with collections of acute inflammatory cells was present at the implantation site.

Group 3: Combined local and systemic delivery of carmustine. Of the 17 eyes in this group 10 were of normal size and shape. In 7 of these 10 eyes small clusters of viable tumour cells were present on the 


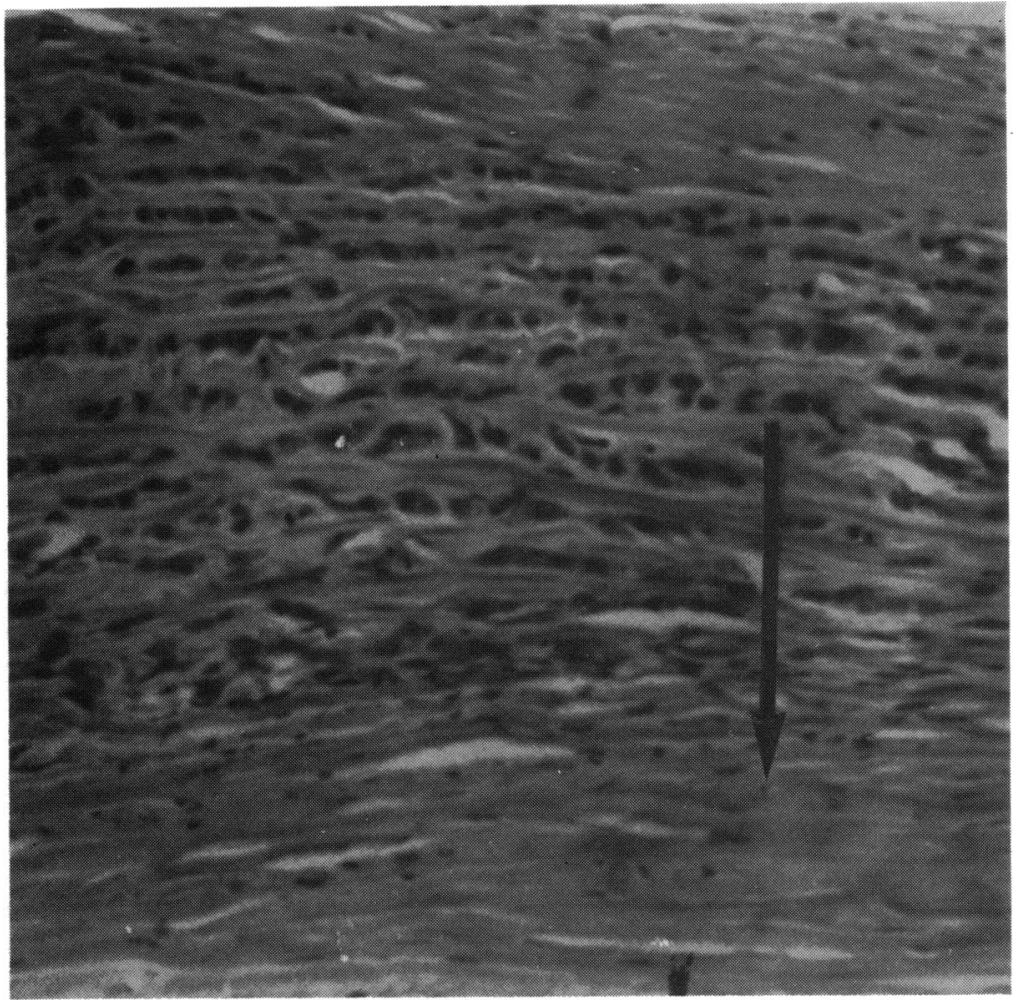

Fig. 5 Necrosis (arrow) of sclera accompanying abscess formed at the site of implanted silicone device (group 3 eye).

(Haematoxylin-eosin, $\times 160)$.

anterior surface of the iris. Some necrotic changes involving the surrounding conjunctiva and the superficial part of the sclera (Fig. 5) with acute inflammatory cells were noted at the implantation site. Only in one eye did an abscess develop round the implanted device.

\section{Discussion}

In attempts to develop a direct delivery system of chemotherapy for intraocular malignancies we have previously shown that administration of carmustine by repeated intravenous or subconjunctival injection retarded tumour growth in a rabbit model with Greene hamster melanoma in the anterior chamber of the eye. The effectiveness of the treatment was considerably enhanced by combining the 2 delivery routes and using a lower dose of carmustine; in about $28 \%$ of animals tumour growth was completely retarded. ${ }^{5}$ It thus seems likely that chemotherapy given in this manner may have a useful role in the treatment of ocular melanoma, particularly as an adjunct to radiation therapy. This may offer an additional alternative to enucleation.

In the present experiments we used the sustainedrelease mechanism for local, continuous delivery of carmustine combined with a lower intravenous dose.
This method is more effective for retarding tumour growth than repeated subconjunctival injections combined with a large intravenous dose of carmustine. However, this method did cause local inflammation and in some cases even tissue necrosis surrounding the implantation site of the device. These side effects may be attributable to sudden local release of a large amount of carmustine-beyond the eye's tolerance-and to the excretion of ethanol from the device just after implantation. Ideally we would like the delivery characteristics to be uniform hour by hour and day by day, within the eye's tolerance level, and for the ethanol to be retained in the device during implantation, as in our recent improvement.9 In addition the device itself must be modified so as to be better tolerated by the eye. We feel that this drug delivery system holds promise for chemotherapy of uveal melanoma in reducing the systemic toxicity of carmustine and increasing the local concentration and effect of the drug. Further efforts to improve the device and to apply this system to the treatment of Greene choroidal melanoma in rabbit eye are under way.

This investigation was supported by US National Institutes of Health grants EY02917 (Dr Liu), EY00327 (Dr Refojo), and EY01917 (Dr Albert), and by Massachusetts Lions Eye Research Fund, Inc. 


\section{References}

1 Schmidt V, Zapol W, Prensky W, Wonders T, Wodinsky I, Kitz R. Continuous cancer chemotherapy: nitrosourea diffusion through implanted silicone rubber capsules. Trans Am Soc Artif Intern Organs 1972; 18: 45-52.

2 Neil GL, Scheidt LG, Kuentzel SL, Moxley TE. Effectiveness of antitumor agents administered subcutaneously to L1210 leukemic mice in silicone rubber devices. Chemotherapy 1973; 18: 27-40.

3 Tator $\mathrm{CH}$. Intraneoplastic injection of CCNU for experimental brain tumor chemotherapy. Surg Neurol 1977; 7: 72-7.

4 Liu HS, Refojo MF, Perry HD, Albert DM. Sustained release of BCNU for the treatment of intraocular malignancies in animal models. Invest Ophthalmol Visual Sci 1979; 18: 1061-7.

5 Liu HS, Refojo MF. Albert DM. Experimental combined systemic and local chemotherapy for intraocular malignancy. Arch Ophthalmol 1980; 98: 905-8.

6 Liu HS, Perry HD, Refojo MF. Tolerance of normal rabbit eyes to the antineoplastic carmustine. Ophthalmologica 1980; 181: 41-6.

7 Henriquez AS, Liu LHS, Refojo MF. Topical administration of the antineoplastic carmustine. Curr Eye Res 1981; 1: 183-7.

8 Refojo MF, Liu LHS, Leong FL, Sidebottom D. Release of a nitrosourea derivative from refillable silicone rubber implants for the treatment of intraocular malignancies. J Bioeng 1978; 2: 437-45.

9 Ueno N. Refojo MF, Liu LHS. Pharmacokinetics of the antineoplastic agent 1,3-bis[2-chloroethyl]-1-nitrosourea (BCNU) in the aqueous and vitreous of rabbit. Invest Ophthalmol Visual Sci 1982; 23: 199-208. 